\title{
A NEW SPECIES OF GALAXIAS (PISCES : GALAXIIDAE) FROM SOUTHERN TASMANIA
}

\author{
by A.P. Andrews
}

(with 3 tables, one text-figure and one plate)

\begin{abstract}
ANDREWS, A.P., 1985 (31:vii): A new species of Galaxias (Pisces : Galaxiidae) from southern Tasmania. Pap. Proc. R.Soc. Tasm. 119:55-60, one pl. https://doi.org/10.26749/rstpp.119.55

ISSN 0080-4703. Tasmanian Museum \& Art Gallery, Hobart, Tasmania, Australia, 7000.

A new species of Galaxias from southern Tasmania is described and figured. The probable mode of origin and relationship with other members of the genus are discussed.
\end{abstract}

Key Words: Galaxiidae, Tasmania

\section{INTRODUCTION}

Since the revision of the family in Tasmania by Andrews (1976), further systematic collecting in various parts of the State has revealed two additional species of Galaxias and three species of Paragalaxias (see McDowall \& Frankenberg, 1981). The finding of another new species of Galaxias in the Mount La Perouse area is not altogether surprising as there appears to have been little, if any, systematic collecting carried out in the area previously.

The Tasmanian members of the genus Galaxias fall naturally into two groups: the broadranging diadromous species $G$. maculatus (Jenyns), $G$. truttaceus Valenciennes and $G$. brevipinnis Gunther; and the lacustrine species which are usually greatly restricted in distribution. Two of the lacustrine species, G. johnstoni Scott and G. pedderensis Frankenberg, were considered by Frankenberg (1969) to be closely related to $G$. olidus Gunther from the Australian mainland. Later Fulton (1978) described another related species, G. fontanus, from the Swan River and all four were treated as related species by McDowall and Frankenberg (1981)

As the species described here also appears to be morphologically most closely related to this group, meristic and morphometric data are provided for all four Tasmanian species by way of comparison.

\section{MATERIALS AND METHODS}

A sample of thirty specimens was collected by the writer (21.111.1984) from the Reservoir Lakes (map reference DM 780 850, Tasmania 1:100000 topographic survey, sheet 8211 , edition 1) in the Mount La Perouse area. The sample was obtained by the use of a fish trap (Andrews, 1976)

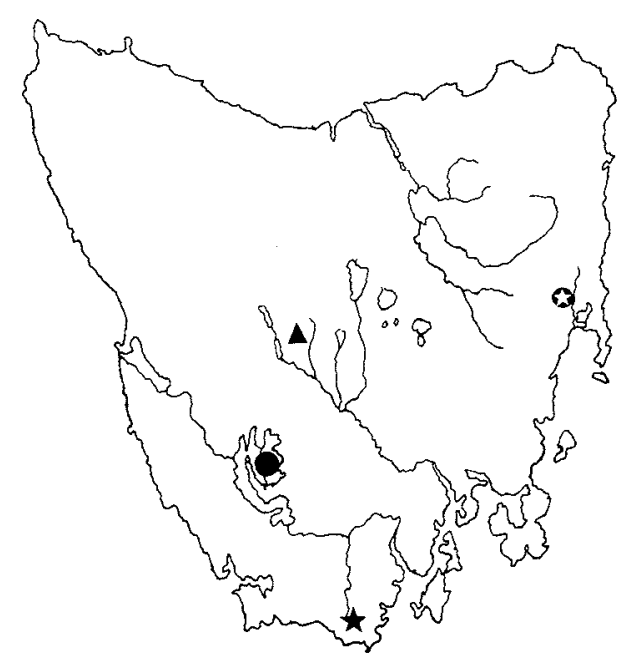

FIG. 1 - Map of Tasmania showing the distributions of Galaxias niger n.sp. and G. fontanus, $G$. johnstoni and $G$. pedderensis. G. pedderensis - solid circle; G. johnstoni - solid triangle; G. fontanus - circle with star; G. niger n.sp. solid star.

and the specimens relaxed using quinaldine, fixed in $10 \%$ formaldehyde and later transferred to $70 \%$ ethanol. Three of the specimens were cleared and stained for osteological study.

Measurements and counts are generally those of Hubbs and Lagler (1958) but following McDowall (1972) all segmented fin rays, branched and unbranched, were counted in the dorsal and anal fins, a procedure not followed by Andrews (1976), and vertebral counts exclude the hypural centra. Meristic and morphometric data are based on a series of twenty specimens which ranged in standard length from $63 \mathrm{~mm}$ to $105 \mathrm{~mm}$. 
Type material has been deposited in the Tasmanian Museum and Art Gallery, Hobart; Queen Victoria Museum and Art Gallery, Launceston; and the Australian Museum, Sydney.

Abbreviations used in the text are as follows: LS standard length (snout tip to hypural joint), HL head length (snout tip to posterior edge of opercular flap), S-DO snout tip to dorsal fin origin, S-VO snout tip to ventral fin origin, PL pectoral fin length, PB-VO pectoral base to ventral fin origin, $V L$ ventral fin length, VB-AO ventral base to anal origin, DCP minimum depth of caudal peduncle, LCP dorsal length of caudal peduncle, ED eye diameter, UJL upper jaw length, LJL lower jaw length, GW gape width, I W interorbital width, HW head width, AMS Australian Museum Sydney, QVML Queen Victoria Museum and Art Gallery Launceston, TMH Tasmanian Museum and Art Gallery Hobart.

\section{SYSTEMATIC ACCOUNT}

\section{Galaxias niger n.sp.}

\section{Diagnosis}

Galaxias niger n.sp. differs from G. johnstoni, $G$. pedderensis and $G$, fontanus by the more numerous pectoral fin rays and vertebrae, the wider head and gape and the heavier pigmentation. It differs from $G$. olidus by the very much wider head and gape, the longer and narrower caudal peduncle, heavier pigmentation and the regular possession of two pyloric caeca. G. niger also differs from $G$. fontanus by the absence of enlarged lateral canine teeth and the presence of only four laterosensory pores in the row below the eyes.

\section{Etymology}

Niger, from the Latin meaning black, is a reference to the heavy pigmentation.

\section{Types}

The species is known from the holotype, TMH No. D1926 (96.0mmLS) and six paratypes that have been distributed as follows: TM H No. D1927, D1928 (101.0mmLS, $106.0 \mathrm{mmLS})$; QVML No. $1984 / 5 / 12,1984 / 5 / 13$ (91.4mmLS, 80.4mmLS); AMS No. I2488.001 (94.0mmLS, $90.0 \mathrm{mmLS})$. All types were collected 21.111 .1984 by the writer from the Reservoir Lakes, southern Tasmania.

\section{Description}

A medium sized species (sensu McDowall \& Frankenberg, 1981), body stout and markedly flattened anteriorly, paired and vertical fins small, pectorals almost circular (plate 1). Anal fin inserted beneath the first third of dorsal base, caudal fin only slightly emarginate. Head large and wide, flat to slightly concave between the orbits. Snout blunt and rounded, jaws very long, lower conspicuously shorter than the upper, angle of jaws extending posteriorly to beneath middle of eye. Two welldeveloped pyloric caeca present, length equal to about twice the diameter. Canine teeth absent.

\section{Colour}

In life, colour is a uniform deep olive brown with numerous large irregular dark brown blocks and bars on the sides, extending well down the sides towards the abdominal surface. All fins a dark translucent brown with conspicuously pigmented rays. A row of about twelve roughly circular brown spots extending from the snout tip along the dorsal midline to the origin of the dorsal fin. A conspicuous dark post-pectoral vertical bar present and usually two, sometimes one, vertical bars on the caudal fin near the base. On preservation the background colour appears as a uniform dark grey and the brown patches a dense black.

\section{Osteology}

Eight or nine branchiostegal rays, gill rakers thin and widely spaced, about ten on each lower side of the anterior arch. All jaw teeth very small, no enlarged lateral canines, a single row of about eight teeth on the inner borders of each mesopterygoid, lingual teeth large. Prepelvic parapophyses not fused to the centra, epipleural ribs present.

\section{Meristic and Morphometric Variation}

The data presented in tables $1-3$ are based on a series of twenty specimens. Comparative data on $G$. johnstoni, G. pedderensis and G. fontanus are based on the following series; G. johnstoni TMH D1116, Clarence Lagoon, Tasmania, 4.IV.1971, (1); TMH D1742, Clarence Lagoon, Tasmania, 17.11.1981, (3); G. pedderensis TMH D1123, Swampy Creek, Tasmania, 23.1.1970, (5); G. fontanus TMH D1740, Swan River, Tasmania, 20.11.1981, (5).

Vertebrae were not counted on the examples of $G$. fontanus used in the present study. Fulton, (1978) gave the range as 50-53.

Values of Student's T, using a pooled estimate of the variance, are listed in table 3 for the tabled body proportions when $G$. niger is compared with the other three species.

\section{Size}

The largest specimen examined in the present study was $105.2 \mathrm{mmLS}$ with the majority falling within the range $65-95 \mathrm{mmLS}$.

\section{Life History}

In common with the other three species considered here, the life history of $G$. niger has not been studied, but females in the material examined showed developing eggs of rather less than $1.0 \mathrm{~mm}$ 


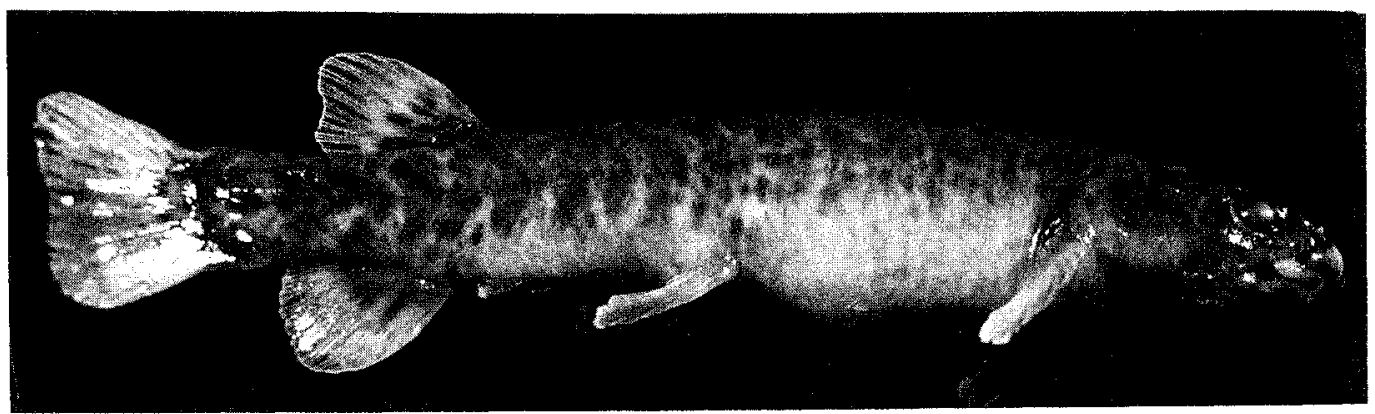

PLATE I - Galaxias niger n.sp. (holotype), Reservoir Lakes, southeastern Tasmania.

diameter which indicate a late winter or early spring spawning.

No evidence of a marine migratory phase in the life cycle was found, juveniles and adults were abundantly distributed throughout the two bodies of water that comprise the type locality. Large shoals of juveniles were observed in the shallows around the edges of the lakes while adults appeared to favour the deeper and more shaded areas.

There was also no evidence to suggest that $G$. niger shares the habitat with other galaxiid species.

\section{Distribution}

At present $G$. niger is known only from the type locality which is the principal source of the Picton River (fig. 1).

\section{DISCUSSION}

The meristic and morphometric data presented in tables $1-3$ indicate that although the four species here considered are superficially similar there are nevertheless consistent and significant differences between them that appear to justify the retention of all as distinct species. The data furthermore indicate that the differences between $G$. niger and the other three species are equally as great, if not greater in some cases than the differences between the three species themselves as evidenced by the number of times the value of Student's $T$ exceeds the $1 \%$ significance level (table 3 ).

Superficially, the colour pattern of $G$. niger although darker and more pronounced, is not dissimilar to two other Tasmanian species, G. cleaveri Scott and G. brevipinnis Gunther. However, the elongated body of $G$. cleaveri and the large paired fins and canine teeth of $G$. brevipinnis allow them to be readily distinguished from $G$. niger.

$G$. niger, G. johnstoni, G. pedderensis and $G$. fontanus each appear to be exclusively confined to one body of water, thus raising the question of how these distributions ca me about. In a previous study
(Andrews, 1976), it was suggested that the Tasmanian distribution of $G$. brevipinnis could best be explained by the assumption that the species used its exceptional climbing ability to invade the upland regions following glacial withdrawal at the end of the Pleistocene. In the same study the ability of $G$. brevipinnis to move from one body of water to a nother was demonstrated by a population which showed evidence of making a juvenile upstream migration from one lake to another. Although the present day distribution of G. brevipinnis, the most widely distributed species in Tasmania, can be explained by this means, it appears unlikely to have applied to G. niger, G. johnstoni, G. pedderensis and $G$. fontanus.

Reservoir Lakes, the habitat of $G$. niger, are adjacent to another permanent water body, the Pigsty Ponds. Whereas the outfall from Reservoir Lakes flows north in to the Picton River, the Pigsty Ponds form the source of the southeasterly flowing D'Entrecasteaux River. The two water bodies are separated by $0.3 \mathrm{~km}$ and a gentle slope which at times of high rainfall is crossed by numerous small temporary streams. The area, however, is evidently impassable to G. niger, as the Pigsty Ponds were found to be densely populated with tadpoles, a condition which in the author's experience is incompatible with the presence of galaxiid fishes. Similarly, G. johnstoni and G. pedderensis appear to be unable to either migrate or extend their habitat from one area to a nother despite the fact that there are continuous aquatic connections which would enable them to do so.

It is significant to observe that the areas inhabited by $G$. niger, $G$. johnstoni and $G$. pedderensis all exhibit abundant evidence of Pleistocene glaciation, (see Derbyshire et al, 1965) and it is possible that glacial activity may have influenced the distribution. McDowall and Frankenberg (1981) show the distribution of G. olidus as being widespread over southeastern Australia and if the similarity between the five species is indicative 
TABLE 1

MERISTIC VARIATION IN FOUR SPECIES OF GALAXIAS

\begin{tabular}{|c|c|c|c|c|c|c|c|c|c|c|c|c|c|c|}
\hline \multirow[t]{2}{*}{ Species } & \multicolumn{4}{|c|}{ Dorsal rays } & \multicolumn{3}{|c|}{ Anal rays } & \multicolumn{7}{|c|}{ Pectoral rays } \\
\hline & 7 & 8 & 9 & 10 & 9 & 10 & 11 & 10 & 11 & 12 & 13 & 14 & 15 & 16 \\
\hline G. niger n.sp. & & 1 & 13 & 6 & 3 & 12 & 5 & & & & & 16 & 21 & $2^{*}$ \\
\hline G. johnstoni & & & 3 & I & 1 & 3 & & & & 3 & 5 & & & \\
\hline G. pedderensis & & 1 & 4 & & 1 & 4 & & & 1 & 7 & $1 *$ & & & \\
\hline G. fontanus & 1 & 3 & I & & 1 & 2 & 2 & 3 & 7 & & & & & \\
\hline
\end{tabular}

\begin{tabular}{|c|c|c|c|c|c|c|c|c|c|c|c|c|c|}
\hline & \multicolumn{3}{|c|}{ Ventral rays } & \multicolumn{10}{|c|}{ Vertebrae } \\
\hline & 6 & 7 & 8 & 49 & 50 & 51 & 52 & 53 & 54 & 55 & 56 & 57 & 58 \\
\hline G. niger n.sp. & 1 & 38 & 1 & & & & & & & & & 1 & 2 \\
\hline G. johnstoni & & 8 & & & & & & 1 & 1 & & $(+)$ & & \\
\hline G. pedderensis & & 10 & & 1 & 2 & 2 & & 1 & 1 & 1 & $(+)$ & & \\
\hline G. fontanus & & 10 & & & & & & & ext & & & & \\
\hline
\end{tabular}

$(+)=$ Data from Andrews (1976)

of a common ancestor, then this common ancestor may have been distributed over southeastern Australia, including Tasmania, prior to the last glacial period. If those populations which occurred in the upland region developed cold tolerant forms then it is possible that they were able to survive the glacial period in a few areas to later remain as relict populations after glacial withdrawal.

$G$. niger ccurs in the headwaters of the Picton River, a tributary of the Huon drainage system, while G. johnstoni and G. pedderensis are found in the headwaters of the Derwent and Gordon River systems respectively (fig. 1). If a common ancestor is indeed the case with these species then it would appear to have been quite widely distributed in much the same way as $G$. olidus on the Australian mainland.

The exception to a glacial-related distribution would appear to be $G$. fontanus. However, as Fulton (1978) has pointed out, this species occurs in a virtual "desert" as far as native fish are concerned and it may be that this species, once established, has managed to survive due to lack of competition.
With the exception of $G$.pedderensis, which marginally shares its habitat with $G$. parvus Frankenberg, none of the species considered here has been found in sympatry with other galaxiid species. It seems therefore not improbable that other such populations may have existed in the past but subsequently been displaced by larger and more adaptable species, such as $G$. brevipinnis. Although Tilzey (1977) found that some galaxiid species could not survive in the presence of introduced salmonids, there has been too little study on the interactions of galaxiid fishes in the wild to enable this hypothesis to be tested.

\section{ACKNOWLEDGEMENTS}

I would like to thank Ms Maryanne Sawle of Sorell for bringing to my attention the species described here and $\mathrm{Mr}$ Alex Buchanan of the Tasmanian Herbarium for assistance with the collection of specimens. 
TABLE 2

MORPHOMETRIC VARIATION IN FOUR SPECIES OF GALAXIAS

Numerator written as a percentage of denominator

\begin{tabular}{lcccccccccccccccc}
\hline & \multicolumn{1}{c}{ G. niger n.sp. } & \multicolumn{1}{c}{ G. johnstoni } & \multicolumn{4}{c}{ G. pedderensis } & \multicolumn{4}{c}{ G. fontanus } \\
& Min. & $\overline{\mathrm{X}}$ & Max. & S.D. & Min. & $\overline{\mathrm{X}}$ & Max. & S.D. & Min. & $\overline{\mathrm{X}}$ & Max. & S.D. & Min. & $\overline{\mathrm{X}}$ & Max. & S.D. \\
HL/LS & 20.3 & 21.7 & 22.9 & 0.76 & 21.7 & 22.0 & 22.4 & 0.30 & 21.3 & 22.6 & 24.8 & 1.25 & 21.4 & 23.7 & 24.8 & 1.22 \\
S-DO/LS & 69.4 & 72.6 & 75.1 & 1.40 & 67.6 & 69.8 & 71.5 & 1.50 & 65.7 & 66.9 & 68.9 & 1.20 & 69.1 & 70.5 & 71.3 & 0.80 \\
S-VO/LS & 48.5 & 51.3 & 53.8 & 1.41 & 52.0 & 54.0 & 55.9 & 1.67 & 50.9 & 52.6 & 54.4 & 1.19 & 50.7 & 52.8 & 54.9 & 1.60 \\
PL/PB-VO & 42.3 & 49.3 & 56.9 & 4.47 & 47.7 & 48.5 & 51.2 & 1.24 & 44.2 & 48.5 & 52.5 & 3.43 & 51.1 & 55.7 & 59.0 & 2.75 \\
VL/VB-AO & 48.0 & 54.0 & 62.9 & 3.64 & 50.0 & 54.7 & 59.7 & 3.69 & 60.3 & 65.5 & 74.1 & 4.41 & 58.2 & 63.6 & 73.6 & 5.55 \\
DCP/LCP & 42.0 & 49.8 & 61.2 & 4.89 & 42.7 & 48.0 & 54.8 & 4.33 & 38.7 & 40.2 & 44.5 & 2.11 & 48.0 & 54.7 & 60.2 & 4.42 \\
LCP/LS & 16.2 & 18.8 & 19.7 & 1.09 & 19.4 & 20.3 & 21.9 & 0.97 & 22.5 & 22.9 & 23.5 & 0.39 & 17.8 & 18.7 & 20.2 & 0.97 \\
ED/HL & 17.9 & 19.6 & 23.2 & 1.65 & 17.2 & 20.5 & 22.2 & 2.00 & 16.8 & 19.4 & 22.4 & 2.17 & 23.8 & 25.9 & 27.9 & 1.67 \\
UJL/HL & 42.6 & 45.4 & 50.8 & 1.99 & 37.4 & 40.0 & 44.3 & 2.80 & 39.2 & 42.0 & 45.4 & 2.19 & 40.8 & 44.8 & 49.2 & 3.13 \\
LJL/HL & 30.7 & 39.0 & 46.2 & 3.27 & 32.2 & 35.9 & 38.7 & 2.69 & 35.4 & 37.5 & 39.9 & 1.79 & 38.5 & 41.7 & 46.0 & 2.75 \\
GW/HL & 44.4 & 49.8 & 60.5 & 3.47 & 40.8 & 43.0 & 45.8 & 1.99 & 37.8 & 42.0 & 45.1 & 2.52 & 31.5 & 36.7 & 41.3 & 3.23 \\
IW/HL & 37.1 & 40.0 & 43.1 & 1.64 & 38.2 & 40.5 & 43.3 & 1.86 & 37.4 & 38.4 & 39.9 & 0.88 & 37.5 & 39.7 & 42.2 & 1.78 \\
HW/HL & 66.4 & 74.6 & 81.7 & 3.93 & 63.7 & 69.7 & 74.0 & 3.73 & 62.7 & 64.1 & 66.4 & 1.30 & 57.7 & 63.0 & 67.5 & 3.30
\end{tabular}


TABLE 3

Values of Student's $T$ as a comparison of G. niger n.sp. with three other species of Galaxias..

\begin{tabular}{lccc}
\hline Ratio & G. johnstoni & G. pedderensis & G. fontanus \\
HL/LS & 1.07 & 1.97 & $* 4.35$ \\
S-DO/LS & $* 3.50$ & $* 8.03$ & $* 3.09$ \\
S-VOL/LS & $* 3.25$ & 1.83 & 1.97 \\
PL/PB-VO & 0.34 & 0.36 & $* 2.94$ \\
VL/VB-AO & 0.34 & $* 5.81$ & $* 4.51$ \\
DCP/LCP & 0.66 & $* 4.15$ & 1.96 \\
LCP/LS & 2.46 & $* 7.88$ & 0.18 \\
ED/HL & 0.93 & 0.22 & $* 7.33$ \\
UJL/HL & $* 4.39$ & $* 3.21$ & 0.51 \\
LJL/HL & 1.70 & 0.95 & 1.64 \\
GW/HL & $* 3.64$ & $* 4.53$ & $* 7.32$ \\
IW/HL & 0.53 & 2.03 & 0.34 \\
HW/HL & 2.20 & $* 5.65$ & $* 5.83$ \\
& $*$ value exceeds $1 \%$ significance level
\end{tabular}

\section{REFERENCES}

ANDREWS, A.P., 1976: A revision of the Family Galaxiidae (Pisces) in Tasmania. Aust.J.Mar. Freshwater Res. 27: 297-349.

DERBYSHIRE, E.D., BANKS, M.R., DAVIES, J.L. \& JENNINGS, J.N., 1965: A glacial map of Tasmania. R.Soc.Tasmania Spec. Publ. No. 2, July $1965,1-11$.

FRANKENBERG, R.S., 1969: STUDIES ON THE EVOLUTION OF GALAXIID FISHES WITH PARTICULAR REFERENCE TO THE AUSTRALIAN FAUNA. Unpub. PhD. thesis, University of Melbourne.

FULTON, W., 1978: A new species of Galaxias (Pisces: Galaxiidae) from the Swan River, Tasmania. Rec.Queen Fic.Mus.Launceston No. 63.

HUBBS, C.L., \& LAGLER, K.F., 1958: FISHES OF THE GREAT LAKES REGION. University of Michigan, Ann Arbor. 213pp.
McDOWALL, R.M., 1972: The species problem in freshwater fishes and the taxonomy of diadromous and lacustrine populations of Galaxias maculatus (Jenyns). J1.Roy.Soc.N.Z. 2(3) 325-367.

MCDOW ALL, R.M. \& FRANK ENBERG, R.S., 1981: The galaxiid fishes of Australia. Rec. Aust.Mus. 33 (10): 443-605.

TILZEY, R.D.J., 1977: Observations on interactions between indigenous Galaxiidae and introduced Salmonidae in the Lake Eucumbene catchment, New South Wales. Aust.J.Mar. Freshwater Res. 27: $551-564$.

(accepted Feb. 21, 1985) 